\title{
Covishield Vaccine Coverage and its adverse effects among the Staffs of Nepalgunj Medical College Banke
}

\author{
Yadav $\mathrm{BK}^{1}$, Choudhary $\mathrm{RC}^{1}$, Shah $\mathrm{GJ}^{1}$, Siddiqui $\mathrm{S}^{1}$
}

\begin{abstract}
Introduction: The corona virus disease-19 pandemic is an ongoing global health crisis and the greatest challenge we have been facing right now in the most peculiar ways. It has caused huge loss of lives and has severely affected the global economy and financial markets. Vaccines are a new critical tool to fight this voracious battle. They have been released in several parts of the world. Although the safety and efficacy of these vaccines have been discussed, we know very little about the post-vaccination experience outside clinical trial situations. Adequate information about the effects of the vaccine can aware the public remove misconceptions and increase vaccine acceptability. Aims: To know the percentage of Covishield vaccine coverage and its adverse effects among the staffs of Nepalgunj Medical College. Methods: A descriptive cross-sectional study was conducted among the vaccinated 91 out of 116 staff members of Nepalgunj Medical College (NGMC), Baijanath Rural Municipality-1, Banke. Results: Out of 91 persons, 15.4\%(14) developed headache, 20\%(18) developed fever, and 8.7\%(17) developed body aches. Of those who developed post-vaccination side effects $47 \%(16)$ of the persons were from age group $36-55 y e a r s, 17 \%(1)$ of them between age group 55-65 years, and none above 65 years developed fever. 20\%(13) of total male and 35\%(5) of total female developed fever within 96 hours after receiving first dose of Covishield AstraZeneca vaccine. Conclusion: Most of the study subjects reported milder side effects which lasted for less than 5 days. No casualties were reported. Local pain and swelling at the injection site, headache and fever were the most common side effects. The side effects were more common in younger individuals and women.
\end{abstract}

Keywords: Adverse effects, COVID-19, Covishield vaccine, SARS-CoV-2, Nepalgunj Medical College

Authors:

1. Dr.Binod Kumar Yadav

2. Prof. Dr. Ram Chandra Choudhary

3. Mr. Gaurav Jung Shah

4. Mr. Saharoj Siddiqui

${ }^{1}$ Department of Community Medicine, Nepalgunj Medical College, Chisapani, Banke

\section{Address for Correspondence:}

Dr. Binod Kumar Yadav

Department of Community Medicine

Nepalgunj Medical College

Chisapani,Banke

Email: vinodyadavcm@gmail.com

\section{INTRODUCTION}

On $31^{\text {st }}$ December 2019, World Health Organization(WHO) was informed about several cases of pneumonia in Wuhan, China. ${ }^{1}$ This infection and virus was declared coronavirus disease(COVID- 19) and severe acute respiratory syndrome corona virus 2 (SARS-CoV-2) respectively. ${ }^{2}$ On $30^{\text {th }}$ January 2020, WHO declared this outbreak as a Public health emergency of international concern. ${ }^{3}$ SARS-CoV-2 is closely related to bat coronavirus and SARS-CoV. ${ }^{4}$ SARS-CoV-2 is the third coronavirus after SARS-CoV(2002) and MERS-CoV(2012). ${ }^{5}$ It exhibits characters of family coronaviridae. ${ }^{6}$ It lies in betacoronavirus $2 \mathrm{~B}$ lineage. ${ }^{7}$ It is a single-stranded RNA virus whose envelope is associated with membrane protein (M), spike protein (S), and envelope protein (E). ${ }^{8}$ The SARS-CoV-2 can be transmitted through direct contact, air, fomites, blood etc. ${ }^{9}$ Fever, cough, shortness of breath, loss of smell and taste are common symptoms of COVID-19. ${ }^{10}$ Till $11^{\text {th }}$ April 2021, a total of 136065997 cases of COVID-19 has been confirmed out of which
2940347 have died and 109455840 have recovered. ${ }^{11}$ The vaccination program began in Nepal on $27^{\text {th }}$ January 2021 after India provided one million doses of the Covishield vaccine. ${ }^{12}$ ChadOx1 ncov-19 coronavirus vaccine (covishield) is given in two different doses of $0.5 \mathrm{ml}$ (Millilitre) each. The second dose is delivered within 4 to 6 weeks after $1^{\text {st }}$ dose. ${ }^{13}$ The efficacy of this vaccine is 70 percent, but it can be more than 90 percent if administered half dose followed by a full dose a month later. ${ }^{14}$ Fever, fatigue, body ache, pain at injection site are some common post-vaccination symptoms. ${ }^{15}$ The study was to know Covishield vaccine coverage and its adverse effects among staff of NGMC.

\section{METHODS}

A descriptive cross-sectional study was conducted at NGMC, Baijanath Rural Municipality-1, Banke. Post-vaccination symptoms were recorded in a schedule. Total number of staff working in NGMC, Baijanath Rural Municipality -1 is 116 out of 
which 91 got vaccinated with first dose of Covishield vaccine. Their vaccination was conducted on $29^{\text {th }}$ and $30^{\text {th }}$ January 2021at NGMC, Kohalpur, Banke. Only the individuals who got vaccinated were included. After the $4^{\text {th }}$ day from the date of vaccination, all the vaccinated staff were given a schedule that included the symptoms after vaccination. The schedule format was made after reviewing different articles.

Statistical analysis: Collected data were entered in specially structured proforma and analyzed statistically in statistical package of social sciences software (SPSS v.20).

\section{RESULTS}

Out of 116 patients, 91 were vaccinated and enrolled in the study.

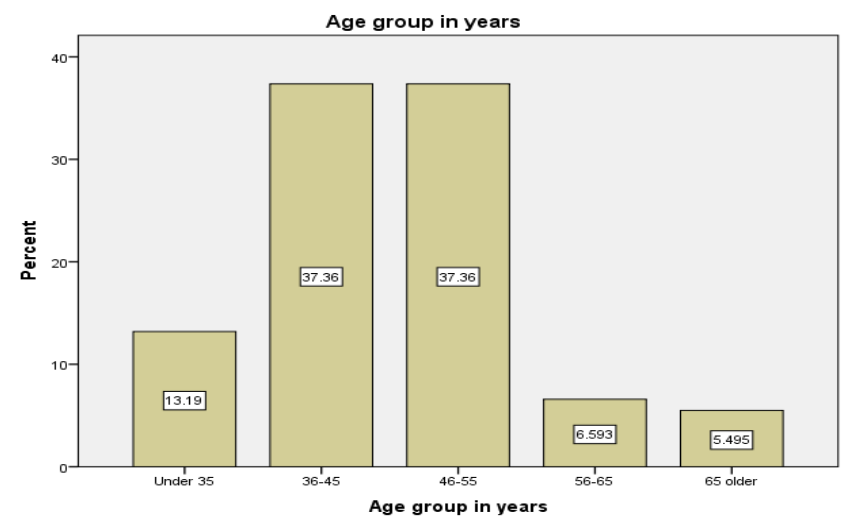

Figure 1:Distribution of vaccines according to duration of fever and age

$13.19 \%(12)$ of study subjects were under 35 years, $37.36 \%(34)$ belonged to the age group of $36-45$ years,37.36\%(34) were from the age group of $46-55$ years, $6.593 \%(6)$ belonged to age group of $56-65$ years, $5.495 \%(5)$ were older than 65 years. The mean age was 46.19 years with range of 45 years. The lowest age was 29 years and the upper age limit was 74 years.

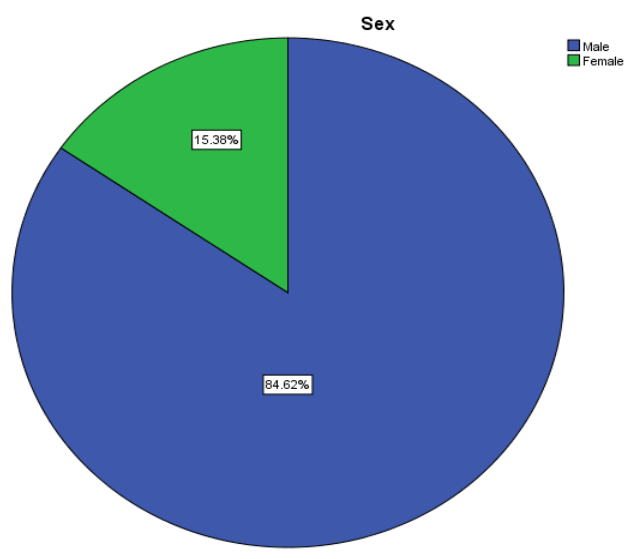

Figure 2: Sex distribution of participants

$84.6 \%$ of total participants (77) were male and $15.4 \%(14)$ were female.

\begin{tabular}{|c|c|c|c|c|c|}
\hline & $\mathrm{Y} / \mathrm{N}$ & Frequency & $\%$ & Mean & $\begin{array}{l}\text { Standard } \\
\text { Deviation }\end{array}$ \\
\hline \multirow{3}{*}{ Giddiness } & No & 80 & 87.9 & \multirow{3}{*}{3.16} & \multirow{3}{*}{8.915} \\
\hline & & & & & \\
\hline & Yes & 11 & 12.1 & & \\
\hline Faint & No & 91 & 100.0 & .00 & .000 \\
\hline \multirow{3}{*}{ Blurred Vision } & No & 89 & 97.8 & \multirow{3}{*}{.79} & \multirow{3}{*}{5.601} \\
\hline & & & & & \\
\hline & Yes & 2 & 2.2 & & \\
\hline \multirow{3}{*}{ Fever } & No & 73 & 80.2 & \multirow{3}{*}{8.70} & \multirow{3}{*}{19.764} \\
\hline & & & & & \\
\hline & Yes & 18 & 19.8 & & \\
\hline \multirow{3}{*}{ Headache } & No & 77 & 84.6 & \multirow{3}{*}{7.91} & \multirow{3}{*}{20.878} \\
\hline & & & & & \\
\hline & Yes & 14 & 15.4 & & \\
\hline \multirow{3}{*}{ Nausea } & No & 89 & 97.8 & \multirow{3}{*}{.79} & \multirow{3}{*}{5.601} \\
\hline & & & & & \\
\hline & Yes & 2 & 2.2 & & \\
\hline \multirow{3}{*}{ Vomit } & No & 91 & 100.0 & \multirow{3}{*}{.00} & \multirow{3}{*}{.000} \\
\hline & & & & & \\
\hline & Yes & 0 & 0.0 & & \\
\hline \multirow{3}{*}{ Cough } & No & 88 & 96.7 & \multirow{3}{*}{2.11} & \multirow{3}{*}{12.724} \\
\hline & & & & & \\
\hline & Yes & 3 & 3.3 & & \\
\hline \multirow{3}{*}{ Sneezing } & No & 90 & 98.9 & \multirow{3}{*}{.26} & \multirow{3}{*}{2.516} \\
\hline & & & & & \\
\hline & Yes & 1 & 1.1 & & \\
\hline \multirow{3}{*}{ Throat Pain } & No & 86 & 94.5 & & \\
\hline & & & & 2.11 & 11.113 \\
\hline & Yes & 5 & 5.5 & & \\
\hline & No & 83 & 91.2 & & \\
\hline Joint Pain & & & & 5.01 & 16.977 \\
\hline & Yes & 8 & 8.8 & & \\
\hline Chills & No & 84 & 92.3 & & \\
\hline & Yes & 7 & 7.7 & 3.16 & 10.857 \\
\hline & No & 77 & 84.6 & & \\
\hline Muscle spasm & & & & 7.38 & 19.495 \\
\hline & Yes & 14 & 15.4 & & \\
\hline & No & 74 & 81.3 & & \\
\hline Bodyache & & & & 9.23 & 21.397 \\
\hline & Yes & 17 & 18.7 & & \\
\hline Itching/ & No & 87 & 95.6 & & \\
\hline Urticaria & Yes & 4 & 4.4 & 1.05 & 4.947 \\
\hline
\end{tabular}

\section{Table I: Distribution of Covishield vaccinated persons according to adverse} effects

Out of $91,10 \%(11)$ of individuals developed giddiness, $20 \%(18)$ developed fever, $2.2 \%(2)$ experienced nausea, 3.3\%(3) developed cough, $1.1 \%(1)$ developed sneezing, $5.5 \%(5)$ developed throat pain, $8.8 \%(8)$ developed joint pain, $7.7 \%(7)$ experienced chills, $15.4 \%(14)$ developed muscle spasm, $18.7 \%(17)$ developed body aches and 4.4\%(4) developed itching. No participants developed vomiting and fainting. Besides these symptoms, few of the subjects were also found to develop gastritis, insomnia due to apprehension, laziness 
and lethargy, redness of the eye, sleepiness and low blood pressure.

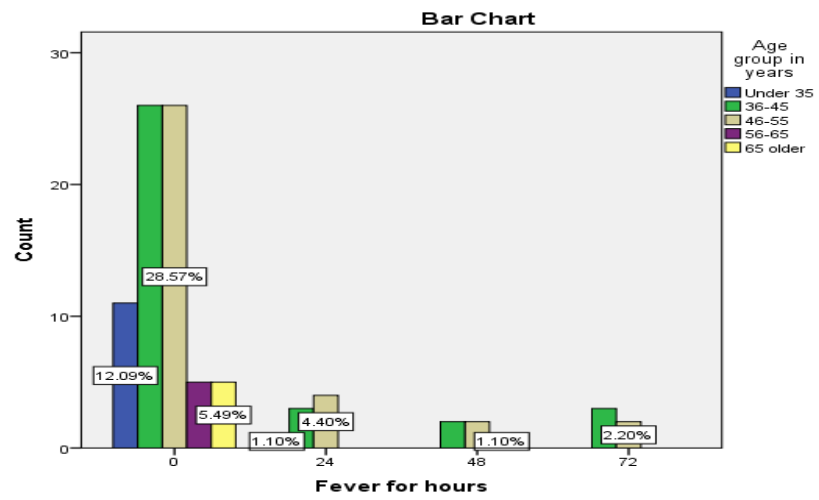

Figure 3: Showing occurrence of fever according to age groups

More than $80 \% 73$ ) of individuals developed no fever at all. $8.8 \%(8)$ of persons had a fever for 24 hours, $5.5 \%(5)$ had it for 48 hours and $5.5 \%(5)$ had a fever lasting for 72 hours. $8.33 \%(1)$ of the study subjects were under $35,23.5 \%(8)$ of them were between $36-45$ years, $23.5 \%$ (8) were in the age group of $46-55$ years, $17 \%(1)$ of them aged $55-65$ years and none above 65 years developed fever within 96 hours of vaccination.

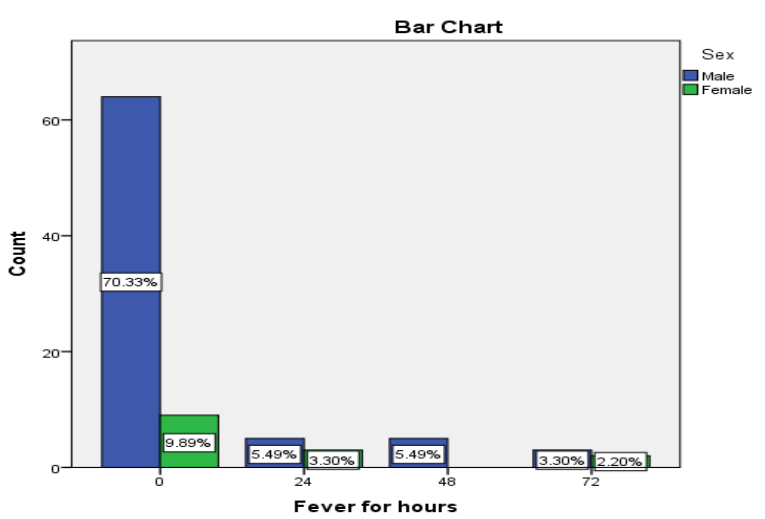

Figure 4: Showing occurrence of fever according to gender

$20 \%(13)$ of total male and $35 \%$ (5) of total female developed fever within 72 hours of vaccination.

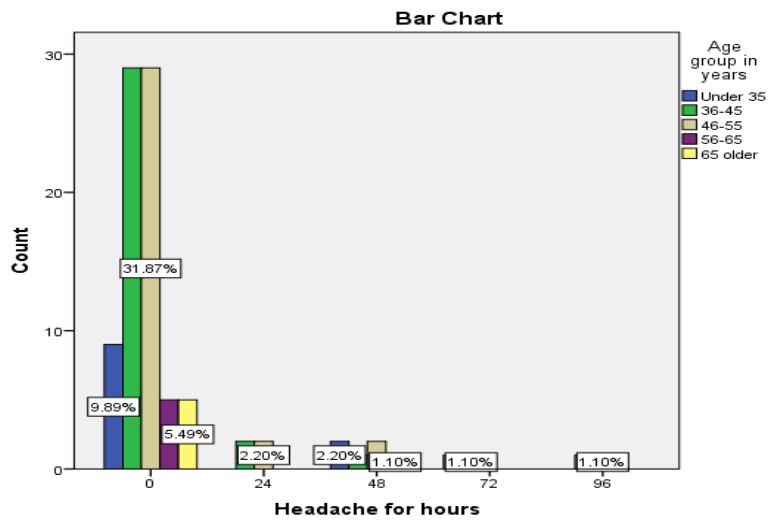

Figure 5: Occurrence of headache according to age groups

$84.6 \%(77)$ of individuals did not develop a headache. $4.4 \%(4)$ developed headache for 24 hours,6.6\%(6) for 48 hours and $2.2 \%(2)$ for 72 hours and $2.2 \%(2)$ developed headache for 96 hours. $25 \%(3)$ of them were under $35,15 \%(5)$ were between the age $36-45$ years, $15 \%$ (5) were aged $46-55$ years, $17 \%(1)$ of subjects in the age group of 55-65 years and none above 65 years developed headache within 96 hours of vaccination.

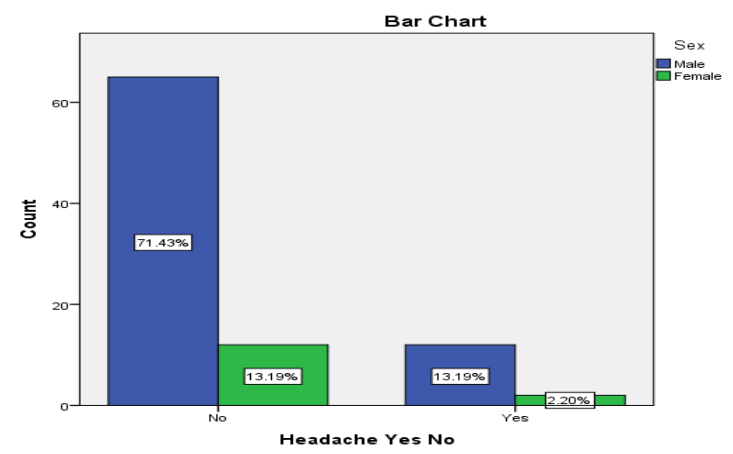

Figure 6: Occurrence of headache according to gender

$15.6 \%(12)$ of total male and $14.2(2) \%$ of total female developed headache within 96 hours of vaccination.

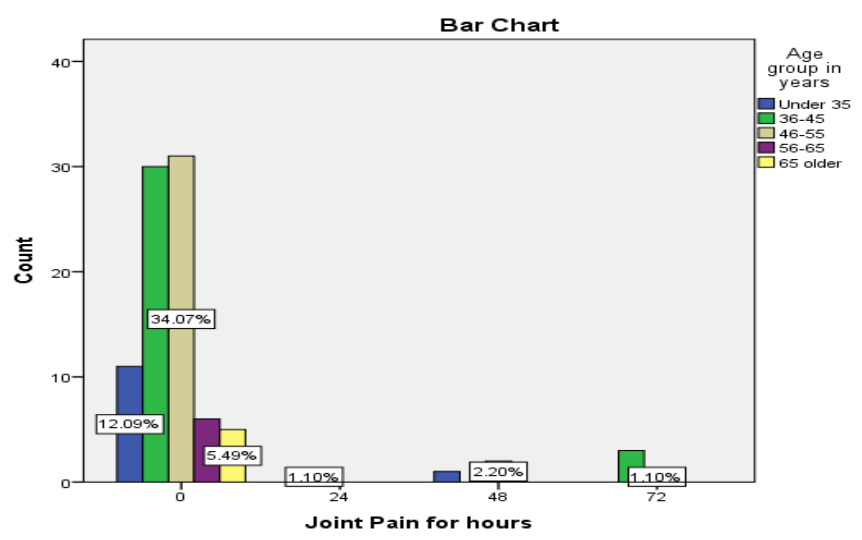

Figure 7: Occurrence of joint pain according to age groups

91.2\% of vaccine did not report joint pain while $1.1 \%$ experienced joint pain for 24 hours, 3.3\% for 48 hours and $4.4 \%$ for 72 hours. $8.33 \%(1)$ of persons were under $35,11.7 \%(4)$ of them were in the age group of $36-45$ years, $8.82 \%(3)$ were aged $46-55$ years and none above 55 years developed joint pain within 96 hours of vaccination.

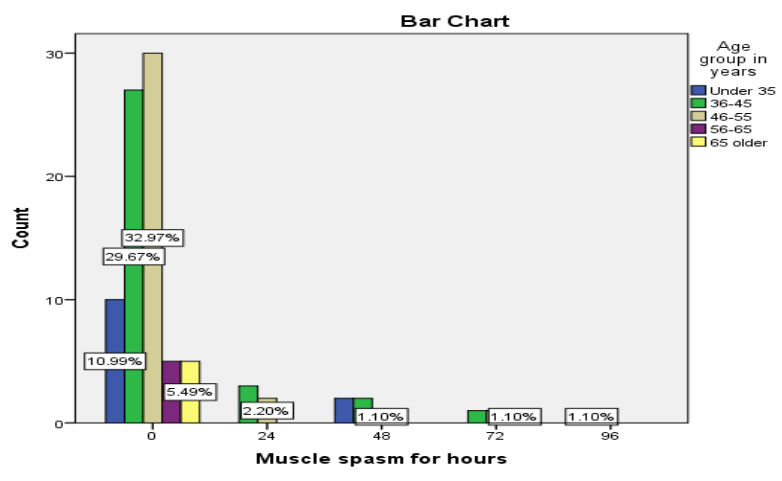

Figure 8: Occurrence of muscle spasm according to age groups 
$84.6 \%(77)$ of individuals had no muscle spasm at all, $5.5 \%(5)$ of them had it for 24 hours, 5.5\%(5) for 48 hours,3.3\%(3) for 72 hours, and $1.1 \%(1)$ for 96 hours after vaccination. $17 \%(2)$ of them were under $35,20.6 \%(7)$ of them were in the age group of $36-45$ years, $11.7 \%(4)$ of persons were in the age group of $46-55$ years, $17 \%(1)$ of subjects were in the age group of 5565 years and no one above 65 years developed muscle spasm within 96 hours of vaccination.

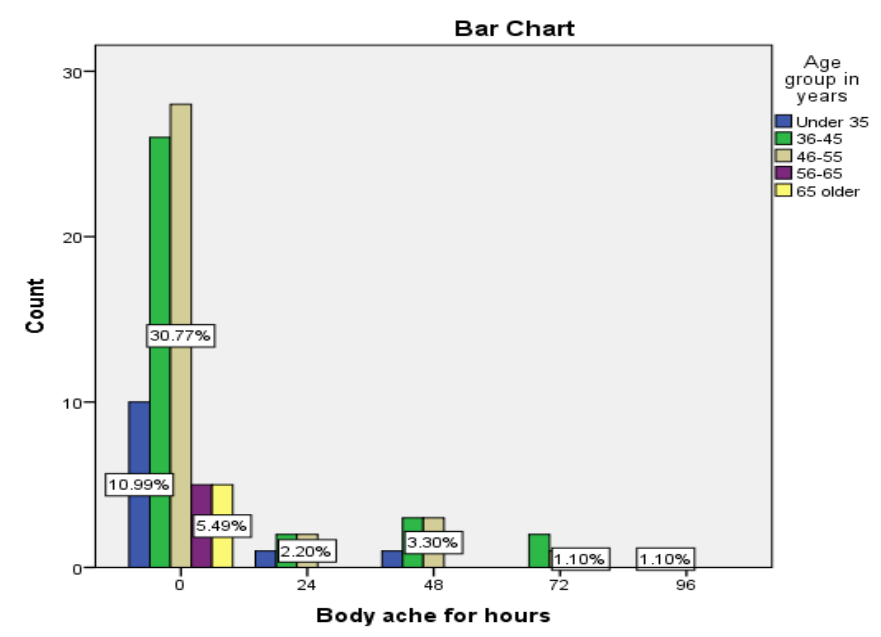

Figure 9: Occurrence of body ache according to age groups

$81.3 \%(74)$ of individuals did not have bodyache, $5.5 \%(5)$ of them had it for 24 hours, $7.7 \%(7)$ had it for 48 hours ,4.4\%(4) had it for 72 hours and 1.1\%(1) had it for 96 hours.17\%(2) of people under $35,23.5 \%(8)$ of people between age group 3645 years, $17.6 \%(6)$ of people between age group $46-55$ years, $17 \%(1)$ of people between age group $55-65$ years and no people above 65 years developed bodyache within 96 hours of vaccination.

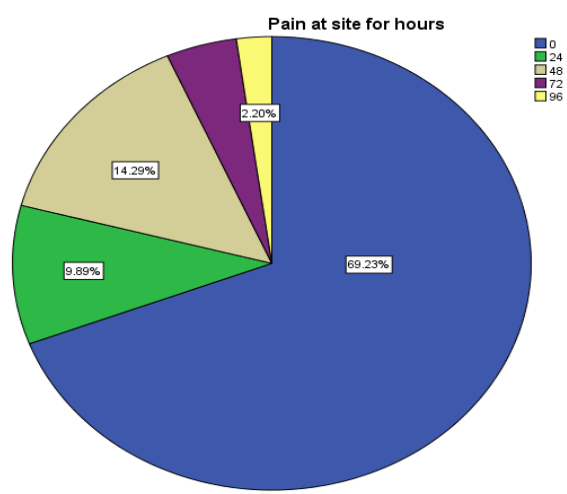

Figure 10: Occurrence of pain at site of injection according to age groups

More than two-thirds (69.23\%) of the individuals had no pain at the site of injection while 9.9\%(9) of them had pain for 24 hours, $14.3 \%(13)$ had it for 48 hours, $4.4 \%$ had it for 96 hours and $2.2 \%(2)$ of individuals had pain for 96 hours.

\section{DISCUSSION}

In a study of vaccination for COVID-19: Experiences, challenges, and solutions in Nepal, it was observed that mild transient headache, dizziness, nausea, tenderness at the injection site were the symptoms to appear earlier on the first day most of which resolved on the second day while the pain at the injection site persisted for more than three days in many individuals. ${ }^{16}$ Similar findings were found in our study. Headache, fever, dizziness, body aches, pain at the injection site, muscle spasms were seen on the first day. Headache, fever, dizziness was present up to $3^{\text {rd }}$ day after which they resolved. However, pain at the injection site, muscle spasms, body aches persisted for four days.

In a survey regarding symptoms following COVID-19 vaccination in India which was conducted online by Rajeev Jayadevan, Ramesh Shenoy, and Anithadevi TS, $45 \%$ of participant experienced tiredness, $44 \%$ developed myalgia, 34\% had fever, $28 \%$ had headache, $27 \%$ had local pain at the injection site, $12 \%$ had joint pain, $8 \%$ had nausea and $3 \%$ had diarrhea. ${ }^{17}$ However, in our survey, it was observed that a comparatively fewer number of subjects developed side effects. Only $20 \%$ developed fever, $15 \%$ had headache, $2 \%$ felt nausea, $9 \%$ had joint pain and $31 \%$ had local pain at the injection site. According to data collected by CDC's artphone app, side effects were experienced by a large number of people after first dose of the Pfizer-BioNTech vaccine in comparison to our study. $68 \%$ of the total participant had pain at the site of injection,29\% experienced fatigue, $26 \%$ had a headache, $17 \%$ had muscle pain, $7 \%$ developed fever,7\% developed joint pain,7 \% developed chills and $7 \%$ felt nausea and $7 \%$ had swelling at the local site of injection. ${ }^{18}$

In research done in the Czech Republic among the health workers, Injection site pain (89.8\%), fatigue (62.2\%), headache (45.6\%), muscle pain (37.1\%), and chills (33.9\%) were the most commonly reported side effects. All the general side effects were more prevalent among the $\leq 43$-year-old group, and their duration was mainly one day $(45.1 \%)$ or three days (35.8\%) following the vaccine. ${ }^{19}$ The same side effects like injection site pain, headache, chills, etc. were also observed in our study however they occurred in a comparatively less proportion of study participants. The prevalence of side effects was more in younger adults more than in older people were also noticed in our study. Fever had developed in $23.5 \%$ of people of age group $36-45$ years, $23.5 \%$ of people of age group $46-45$ years while only $17 \%$ of persons of age group $46-55$ years developed fever and it was found to be absent in individuals of 65 years and above. The obtained result related to headache, muscle spasm, and joint pain also exhibits their prevalence more in younger adults. Feeling of dizziness, decreased appetite, abdominal pain, enlarged lymph nodes, excessive sweating, itchy skin, or rash are some uncommon side effects of this vaccine. ${ }^{20}$ Out of these, only dizziness and abdominal pain in some individuals were reported in our study. A preliminary report released on medrxiv has also reported only mild selflimiting adverse effects of this vaccine. ${ }^{21}$ An article on the site medical news today reported that the side effects were more frequent in men. ${ }^{22}$ In our study, most of the symptoms like fever, headache were more prevalent in women than men. $20 \%(13)$ of total male and $35 \%(5)$ of total female developed fever and $15.6 \%(12)$ of total male and $14.2(2) \%$ of total female developed headache within 96 hours of vaccination. 


\section{LIMITATIONS}

Relatively small sample size and the coverage of only one medical college. As the sample size was small, it may underestimate or overestimate the adverse effects of Covishield vaccine. The adverse effects of the second dose of this vaccine has not been studied in this research. The symptoms were recorded for only four days after vaccination. Efficacy was not measured. There were no participants below 29 years and very few participants above 60 years of age.

\section{CONCLUSION}

Participants of this study reported milder side effects which were short lived, not lasting more than four days. No participants were hospitalized due to the side effects of this vaccine. No cases of death or any serious events were reported. Pain at the injection site, swelling, headache, fever, joint pain, nausea etc were the most common side effects. The side effects were more common in younger individuals and women.

\section{ACKNOWLEDGMENTS}

We express our sincere gratitude towards Mr. Rameshwar Yadav, Er. Firoj Siddiki, Ms. Aliya Ghufran, Mr. Prashant Thakur and Dr. Rahul Yadav for their support in our study.

\section{REFERENCES}

1. Outbreaks and emergencies [internet].World Health Organization. 2020[22 January 2020] available from: $\underline{\text { https:// }}$ web.archive.org/ web / 20200122103944/ https://www. who.int/ westernpacific/ emergencies/ novel-coronavirus

2. Naming corona virus disease and the virus that caused it[internet].World Health Organization. Available from: https://www.who.int/emergencies/diseases/novelcoronavirus-2019/technical-guidance/naming-t

3. Covid-19 public health emergency of international concern(PHEIC) global research and innovation forum[Internet]. World Health Organization. 2020[12 February 2020]Available from:https://www.who.int/ publications/m/item/covid-19-public-health-emergencyof-international-concern-(pheic)-global-research-andinnovation-forum

4. Mackenzie, J. S., \& Smith, D. W. (2020). COVID-19: a novel zoonotic disease caused by a coronavirus from China: what we know and what we don't. Microbiology Australia, MA20013. Advance online publication. https://doi. org/10.1071/MA20013

5. Zhu, Z., Lian, X., Su, X. et al. From SARS and MERS to COVID-19: a brief summary and comparison of severe acute respiratory infections caused by three highly pathogenic human coronaviruses. Respir Res 21, 224 (2020). https:// doi.org/10.1186/s12931-020-01479-w

6. Wang Mei-Yue, Zhao Rong, et al. SARS-CoV-2: Structure, Biology, and Structure-Based Therapeutics Development[Internet]. Frontiers in Cellular and Infection
Microbiology.2020;10;72 Available from: https://www. frontiersin.org/article/10.3389/fcimb.2020.587269

7. Lai C. C., Shih T. P., Ko W. C., Tang H. J., Hsueh P. R. (2020). Severe acute respiratory syndrome coronavirus 2 (SARSCoV-2) and coronavirus disease-2019 (COVID-19): The epidemic and the challenges. Int. J. Antimicrobial Agents 55, 105924. doi: 10.1016/j.ijantimicag.2020.105924

8. Brian D. A., Baric R. S. (2005). Coronavirus genome structure and replication. Curr. Topics Microbiol. Immunol. 287, 1-30. doi: 10.1007/3-540-26765-4_1

9. Transmission of SARS-CoV-2: implications for infection prevention precautions[Internet].World Health Organization [29 march 2020]. Available from: https://www.who.int/ news-room/commentaries/detail/transmission-of-sars-cov2-implications-for-infection-prevention-precautions.

10. Interim Clinical Guidance for Management of Patients with Confirmed Coronavirus Disease (COVID-19) [internet]. Centers For Disease Control And Prevention. Available from: https://www.cdc.gov/coronavirus/2019-ncov/hcp/clinicalguidance-management-patients.html\#print

11. Coronavirus cases[internet].Worldometer.. Available from: https://www.worldometers.info/coronavirus/coronaviruscases/

12. Nepal begins first phase of Covid-19 vaccination drive[internet].The Kathmandu Post. cited( 18 april 2021). Available from: https://kathmandupost.com/ health/2021/01/27/nepal-begins-first-phase-ofvaccination-drive-against-covid-19

13. ChAdOx1 nCoV- 19 Corona Virus Vaccine (Recombinant) COVISHIELD ${ }^{\mathrm{TM}}[$ Internet].Serum Institute Of India.Available from: https://www.seruminstitute.com/product covishield. php

14. Covaxin vs covidshieldprice,possible 'side effects', efficacay,second dose timing[internet]. MintAvailable from: https://www.livemint.com/news/india/ covaxin-vs-covishield-price-possible-side-effects-efficacysecond-dose-timing-11619319042470.html

15. Coronavirus vaccine: How to cope with post-vaccination side effects? Here's what doctors have to say [internet].Times Of India.. Available from: https://timesofindia.indiatimes.com/ life-style/health-fitness/health-news/coronavirus-vaccinehow-to-cope-with-post-vaccination-side-effects-hereswhat-doctors-have-to-say/photostory/81566623.cms

16. Sah R, Shrestha S, Mehta R, et al. AZD1222 (Covishield) vaccination for COVID-19: Experiences, challenges, and solutions in Nepal. Travel Med Infect Dis. 2021;40:101989. doi:10.1016/j.tmaid.2021.101989

17. Rajeev jayadevan,Rameshshenoy,antihadevi TS survey of symptoms following COVID-19 vaccination in indiamedRxiv 2021.02.08.21251366Available from: https://www.medrxiv. org/content/10.1101/2021.02.08.21251366v1 
18. Tom shimabukuro.covid-19 vaccine safety update[internet]. Centers For Disease Control And PreventionAvailable from: https://www.cdc.gov/vaccines/acip/meetings/downloads/ slides-2021-01/06-COVID-Shimabukuro.pdf

19. Riad A, Pokorná A, Attia S, Klugarová J, Koščík M, Klugar M. Prevalence of COVID-19 Vaccine Side Effects among Healthcare Workers in the Czech Republic. Journal of Clinical Medicine 2021;10:1428

20. Covid 19 vaccines Covishield, Covaxin 'side effects': What we know so far[Internet].Financial ExpressAvailable from: https://www.financialexpress.com/lifestyle/health/covid19-vaccines-covishield-covaxin-side-effects-what-we-knowso-far/2176274/

21. Kataria S, et al. A Real World Evaluation of the safety and immunogenicity of the Covishield vaccine, ChAdOx1 nCoV19 Corona Virus Vaccine (Recombinant) in Health Care Workers (HCW) in National Capital Region (NCR) of India: A preliminary report. medRxiv, 2021. Available from: https:// www.medrxiv.org/content/10.1101/2021.04.14.2125545 $\underline{2 v 1}$

22. MinseoJeong. Global COVID-19 vaccine summary: Side effects. Medical News Today. [march 22,2021]Available from: https://www.medicalnewstoday.com/articles/globalcovid-19-vaccine-summary-side-effects. 